\title{
Assessment of nutritional status and its effect on academic performance in school children of Jazan, Kingdom of Saudi Arabia
}

\author{
Maseer Khan ${ }^{1 *}$, Mohd Shanawaz ${ }^{2}$, Amani Awwadh Altoaibi², Abdul Aziz Behees Gaba1, \\ Osama Ismail Saqeeh ${ }^{1}$, Abdur Rahman Ali Mashali ${ }^{1}$
}

Department of ${ }^{1}$ Epidemiology, ${ }^{2}$ Health education, Faculty of Public health and Tropical Medicine, Jazan University, Jazan, Kingdom of Saudi Arabia

Received: 20 January 2020

Revised: 05 March 2020

Accepted: 06 March 2020

*Correspondence:

Dr. Maseer Khan,

E-mail: drmaseerkhan@gmail.com

Copyright: (c) the author(s), publisher and licensee Medip Academy. This is an open-access article distributed under the terms of the Creative Commons Attribution Non-Commercial License, which permits unrestricted non-commercial use, distribution, and reproduction in any medium, provided the original work is properly cited.

\section{ABSTRACT}

Background: Adolescence is the tender and vital period in the life of a person. It is a transitional stage of physical and psychological development that generally occurs during the period from puberty to legal adulthood. Nutrition is the prime requirement of the adolescents for their physical and mental growth. The aim of the study was to assess the nutritional status of the primary school going children in Jazan, KSA and to analyze the association of nutrition status with academic performance of school going children in Jazan, KSA.

Methods: This study involved 4 schools chosen randomly from the government schools of Jazan. 7th and 8th class children were considered for the study. Required ethical approval bearing reference number 28943 dated 20/6/1440 was taken from the Institutional ethical committee. Study sample: 200 collection of the data: data collected from the schools of Jazan selected randomly in the school working hours.

Results: $60 \%$ of the sample is in the age group $17-18$ years. $30 \%$ of the sample were having more than 5 siblings. $16 \%$ of the parents were illiterates. The proportion of students taking milk products more than 3 times in the week (79.1\%) were found to be performing well in the schools than the students consuming less than 3 days week. Strong association was found between performance of the students and parent's education as the educated parents' children were performing well.

Conclusions: Good nutrition for the growing kids was found to be associated with academic performance of the students.

Keywords: Nutritional status, Academic performance, Jazan, Diet

\section{INTRODUCTION}

Adolescence is the tender and vital period in the life of a person. Guardians of the children should pilot this highly turbulent period. $^{1}$ It is a transitional stage of physical and psychological development that generally occurs during the period from puberty to legal adulthood ${ }^{2}$. Nutrition is the prime requirement of the adolescents for their physical and mental growth. Proper and quality nutrition affects the academic performance of the students. Nutritional status is the health condition which is influenced by intake of the nutrients and its utilization in the body. ${ }^{3}$

Proper diet and nutrition are always related to the academic performance. Many studies done in the past showed the academic performance is affected by hunger, malnutrition, and micronutrient deficiency. ${ }^{4-6}$ Undernourished children have been shown to have reduced attendance, attention span, and academic 
performance and also were found to have experiencing more health problems compared to well-nourished children. ${ }^{4,7}$ Few studies represented that breakfast is very essential for the cognition, behavior, and academic performance of school-age children. ${ }^{4,8}$ Consumption of proper breakfast seems to have direct impact on specific cognitive tasks for the school going children..$^{4,8}$

For better academic performance proper cognitive development of the brain is required and it is influenced by the nutrition from outside (dietary intake) sources in order to maintain the amount of neurons and functioning of neurotransmitters. ${ }^{9}$

Lacunae still exist in the knowledge regarding the performance in the school in relation to the proper diet.

\section{Rationality from community perspective}

Adolescence is the developmental period in which physical psychosocial and sexual growth occurs in the human being. Students will be entitled various academic activities warranting enhanced cognitive ability so it is the pressing need for taking care of dietary and nutritional status of the adolescent otherwise which the children may enter into malnutrition hampering the physical growth and academic performance in the schools. It was proved that children who don't take quality food suffer physically. At the age ranging 10- 14 years tremendous physical and cognitive growth occurs and approximately $90 \%$ of the brain development occurs before attaining 13 years. ${ }^{10}$ Brain development slows down in severe malnutrition and cerebral cortex reduces in size with decreased number of neurons. ${ }^{11}$ As there is direct effect of malnutrition on brain development implies the direct effect on academic performance of primary school children $^{12}$. The present study was done to advise the students, teachers and guardians regarding healthy and quality diet for the children such that kids grow as effective and prosperous citizen of the country.

The objective of the study was to assess the nutritional status of the primary school going children in Jazan, KSA and to analyze the association of nutrition status with academic performance of school going children in Jazan, KSA.

\section{METHODS}

This study involved 4 schools picked randomly from the Government schools of Jazan. $7^{\text {th }}$ and $8^{\text {th }}$ class children were considered for the study. Required ethical approval taken from the Institutional ethical committee.

For convenience all the schools were divided into 4 zones (Eastern, western, northern and southern).
By using random number generator and applying random sampling method in each zone, one school was selected from the zone

Al-Andalus Middle school-Northern region. Mohammed bin Ali Al-sunoosi high school-eastern region. Mua'th bin Jabal Middle School-western region. Mua'th bin Jabal high school- southern region.

\section{Data collected from the selected 4 schools}

School based cross-sectional study. Study Sample: 200. Study period: August 2018.

\section{Inclusion criteria}

Male students belonging to higher class $7^{\text {th }}$ and $8^{\text {th }}$ considered for the study.

\section{Exclusion criteria}

Students were informed prior and consent taken from the school authority. Students who are unwilling to participate in the study were excluded.

\section{Collection of the data}

Data collected from the schools of Jazan selected randomly in the school working hours.

\section{Anthropometry}

Anthropometric indices recorded as per WHO Anthropometric standards. ${ }^{13}$ The weight recorded approximated to the nearest $0.1 \mathrm{~kg}$ by bathroom weighing scale and the height to $0.5 \mathrm{~cm}$ using a SECA 284 height measuring scale.

\section{Operational definition of nutritional status}

BMI calculated by the formula: $\mathrm{BMI}=$ weight $(\mathrm{kg}) /$ height $\left(\mathrm{m}^{2}\right)$. All children weighed and height will be taken in standing position Based on the BMI of the children nutritional status assessed. A pre-designed and prevalidated questionnaire administered to collect information.

\section{Investigators}

A team of 3 students were re-oriented in techniques of taking anthropometric measurements. After discussion pilot project done to learn and correct the logistics and practical liabilities.

Collection of data was done in school hours, as permitted by the authorities for not disturbing the routine schedule of the students. Each participant examined by one investigator in order to remove inter-observer variations. After interview the anthropometric measurements were 
taken. All the data entered into the questionnaire simultaneously.

\section{Evaluation of the quality of the feed}

The choice of foods guided by their potential impact on food quality, their different effects on nutritional status, their presence in the school environment and their popularity among schoolchildren Questions were asked to students for 7 days like how many days you eat these foods. These different foods concerned vegetables, fruits, meat, fish, liver, tofu and caramel, candy and chewing gum, biscuits and chocolates, yoghurt, dairy products and sweetened beverages. Mid semester total marks considered for academic performance.

\section{Data entry and analysis}

The data entered in microsoft excel 2010 and analyzed. Descriptive statistics (mean, standard deviation and percentiles) utilized to explore the data. Results with $\mathrm{p}<0.05$ are taken as significant.

\section{RESULTS}

$60 \%$ of the sample size belongs to the age group 17-18 years. $90 \%$ of the sample size were residing in urban area of Jazan province. $78 \%$ of the sample's household size is less than $5.30 \%$ of the mothers were post graduates and $9 \%$ were illiterates. $17 \%$ of the fathers were post graduates and $24.5 \%$ were illiterates.

Average age of the sample size was 16.35 years \pm 1.75 , Average BMI of the students was found to be $26.6 \pm 7.8$ (pre obese).

Students consuming non veg diet more than 3 times were found to perform low in academics when compared to students consuming non veg diet less than 3 times and this association was statistically significant $(\mathrm{p}=0.03)$. Legumes $(p=0.000)$ and cookies $(p=0.000)$ ingestion was associated positively with performance and found to be highly statistically significant.

Table 1: Socio-demographic characteristics of the study sample.

\begin{tabular}{|c|c|c|c|}
\hline Variables & & $\mathbf{N}$ & $\%$ \\
\hline \multirow{3}{*}{ Age group (in years) } & $11-13$ & 10 & 5 \\
\hline & $14-16$ & 70 & 35 \\
\hline & $17-18$ & 120 & 60 \\
\hline \multirow{2}{*}{ Residential area } & Urban & 180 & 90 \\
\hline & Rural & 20 & 10 \\
\hline \multirow{2}{*}{ Household size } & $<5$ & 156 & 78 \\
\hline & $\geq 5$ & 44 & 22 \\
\hline \multirow{2}{*}{ Number of siblings } & $<5$ & 140 & 70 \\
\hline & $\geq 5$ & 60 & 30 \\
\hline \multirow{5}{*}{ Mother's education } & Illiterate & 18 & 9 \\
\hline & Primary & 32 & 16 \\
\hline & Secondary & 37 & 18.5 \\
\hline & Graduate & 53 & 26.5 \\
\hline & Post graduate & 60 & 30 \\
\hline \multirow{5}{*}{ Father's education } & Illiterate & 49 & 24.5 \\
\hline & Primary & 42 & 21 \\
\hline & Secondary & 47 & 23.5 \\
\hline & Graduate & 28 & 14 \\
\hline & Post graduate & 34 & 17 \\
\hline
\end{tabular}

Students consuming milk products more than 3 times per week were found to have performed well in academics. Fast food consumption was associated with poor performance in schools. Fruits, cereals and vegetables and juices consumption was not found to be associated with performance.

Mother's education was found to be significantly associated with academic performance of the students. Parent's education is found to be associated directly to the performance of the students.
Table 2: Assessment of nutritional status by Anthropometry $(\mathrm{n}=\mathbf{2 0 0})$.

\begin{tabular}{|l|l|}
\hline Variable & $\begin{array}{l}\text { Total population } \\
\text { Mean } \pm \text { SD }\end{array}$ \\
\hline Age (in years) & $16.35 \pm 1.75$ \\
\hline Height & $162.4 \pm 7.4$ \\
\hline Weight & $71.15 \pm 1.85$ \\
\hline BMI $\left(\mathbf{k g} / \mathbf{m}^{\mathbf{2}}\right)$ & $26.6 \pm 7.8$ \\
\hline
\end{tabular}


Table 3: Assessment of diet per week and its effect on academic performance.

\begin{tabular}{|c|c|c|c|c|c|}
\hline Variables & Frequency & Poor performance (\%) & Good performance (\%) & Total & P value \\
\hline \multirow{3}{*}{ Non veg } & $<3$ & $86(56.3)$ & $69(43.7)$ & 155 & \multirow{3}{*}{0.03} \\
\hline & $>3$ & $34(75)$ & $11(25)$ & 45 & \\
\hline & Total & $120(60)$ & $80(40)$ & 200 & \\
\hline \multirow{3}{*}{$\begin{array}{l}\text { Fruits and } \\
\text { vegetables }\end{array}$} & $<3$ & $81(59)$ & $56(41)$ & 137 & \multirow{3}{*}{1.00} \\
\hline & $>3$ & $39(61.9)$ & $24(38.1)$ & 63 & \\
\hline & Total & $120(60)$ & $80(40)$ & 200 & \\
\hline \multirow{3}{*}{ Cookies } & $<3$ & 70 & 20 & 90 & \multirow{3}{*}{-0.000} \\
\hline & $>3$ & 50 & 60 & 110 & \\
\hline & Total & 120 & 60 & & \\
\hline \multirow{3}{*}{ Cereals } & $<3$ & $60(60)$ & $40(40)$ & 100 & \multirow{3}{*}{1.00} \\
\hline & $>3$ & $60(60)$ & $40(40)$ & 100 & \\
\hline & Total & $120(60)$ & $80(40)$ & 200 & \\
\hline \multirow{3}{*}{$\begin{array}{l}\text { Milk and } \\
\text { dairy } \\
\text { products }\end{array}$} & $<3$ & $61(70.09)$ & $25(29.01)$ & 86 & \multirow{3}{*}{0.005} \\
\hline & $>3$ & $25(21.9)$ & $89(79.1)$ & 114 & \\
\hline & Total & 86 & 114 & & \\
\hline \multirow{3}{*}{ Legumes } & $<3$ & $110(68.7)$ & $50(31.3)$ & 160 & \multirow{2}{*}{0.000} \\
\hline & $>3$ & $10(25)$ & $30(75)$ & 40 & \\
\hline & Total & $120(60)$ & $80(40)$ & 200 & \\
\hline \multirow{3}{*}{ Juices } & $<3$ & $70(53.8)$ & $60(46.2)$ & 130 & \multirow{2}{*}{0.15} \\
\hline & $>3$ & $50(71.4)$ & 20 (28.6) & 70 & \\
\hline & Total & $120(60)$ & $80(40)$ & 200 & \\
\hline \multirow{3}{*}{ Fast foods } & $<3$ & $100(66.6)$ & $50(33.3)$ & 150 & \multirow{3}{*}{0.0001} \\
\hline & $>3$ & $20(40)$ & $30(60)$ & 50 & \\
\hline & Total & 120 & 80 & 200 & \\
\hline
\end{tabular}

Table 4: Effect of parent education on academic performance of the students.

\begin{tabular}{|llll|}
\hline Variable & & Poor performance (\%) & Good performance (\%) \\
\cline { 2 - 4 } Mother education & Illiterate & $14(7)$ & $6(3)$ \\
\cline { 2 - 4 } Father education & Primary and more & $19(9.5)$ & $161(80.5)$ \\
\cline { 2 - 4 } & Illiterate & $38(19)$ & $11(5.5)$ \\
\cline { 2 - 4 } & Primary and more & $28(14)$ & $123(61.5)$ \\
\hline
\end{tabular}

Approximately $30 \%$ of the sample was found to be obese when examined for general appearance. $23.5 \%$ were found to have yellowing of teeth and $11 \%$ have dental caries and were advised to approach dentist. School authority was also informed about the same. $10.5 \%$ of the sample size were having bleeding gums.

Table 5: Clinical examination of the students.

\begin{tabular}{|lll|}
\hline Variable & & Percentage (\%) \\
\hline \multirow{2}{*}{$\begin{array}{l}\text { General } \\
\text { appearance }\end{array}$} & Thin built & 15.5 \\
\cline { 2 - 3 } & Normal & 55 \\
\cline { 2 - 3 } Hair & Obese & 29.5 \\
\hline \multirow{3}{*}{ Teeth } & Normal & 78 \\
\cline { 2 - 3 } & Pigmented & 22 \\
\hline \multirow{2}{*}{ Gums } & Normal & 65.5 \\
\cline { 2 - 3 } & Yellowing of teeth & 23.5 \\
\cline { 2 - 3 } & Dental caries & 11 \\
\cline { 2 - 3 } & Normal & 89.5 \\
\hline
\end{tabular}

\section{DISCUSSION}

Assessment of nutritional status of the students and assessing its influence on the academic performance would predict and can be helpful in generating insights on useful nutritional programs and strategies to improve health status of the children accounting to the healthy future of the nation. On an average, age of school children was $16.35 \pm 1.75$ years in the current study.

Assessment of nutritional status showed that average BMI for the school students was in pre obese category. In the study done by Alswat et al in Taif it was found significant association between obesity and poor academic performance. ${ }^{14}$ World health organization states that pre obesity and lack of physical activity is associated with non-communicable diseases in adult and middle age. Obesity and academic performance have robust negative association. Few studies documented decreased cognitive function coupled with loss of abstract reasoning and attention span with increased weight of child. ${ }^{15}$ 
Parents education was found to be influencing the academic performance of the students and the similar results were obtained in the study done by Alswat et al and Lee et al, so it can be inferred that family environment influences the academic performance of the students. ${ }^{14,16}$ Mothers education had more influence on the academic performance of the students when compared with father's education status. This solidifies the need of female literacy.

With the average BMI of the school children in the current study in the pre-obese category, it was always preferable to give healthy and nutritious diet to the children and parents need to be cautious about fast-food consumption by the school children. In the study it was found that healthy foods like legumes $(p=0.0001)$, cookies $(p=0.0001)$ and milk products $(p=0.005)$ consumption was associated with good academic performance of the students.

In the present study Fast- food consumption was found to be inversely related to the academic performance $(p=0.0001)$. similar results were shown in the study done by Zhang et al. ${ }^{17}$ Increased intake of poly unsaturated fatty acids and decreased intake of cholesterol were associated with good academic performance. Increased consumption of fast foods in the tender adolescent age may lead to obesity and non-communicable diseases in adult age.

Fruits, vegetables and juices were not found to be associated with performance however in the study done in Gaza fruits and vegetables consumption was significantly associated with academic performance. ${ }^{18}$

Upon clinical examination of the students it was found that approximately $30 \%$ are obese and $15 \%$ are undernourished. similar results were noted in the study done by Hazmi et al. ${ }^{19}$ In this study it was found that occurrence of obesity is increasing by age. As it is a known fact that obesity at an earlier age may predispose to non- communicable diseases, it is always advisable to restrict the consumption of fast foods, sweetened beverages, oil rich foods etc. Proper training for the students regarding the physical activity is a pressing need now in the kingdom. However, in the current study undernourishment was also found to a considerable percentage of $15 \%$.

Approximately one third of the sample size witnessed dental problems including yellowing of teeth and dental caries. Foods and drinks with a pH below 5.0-5.7 (acidic) known to trigger dental erosion effects. Low calcium and fluoride ion concentration with low $\mathrm{pH}$ indicate high erosive potential. ${ }^{20}$ To avoid dental caries dietary restrictions are required.

\section{Limitations of the study}

The study was done in the limited sample so generalization of the results may not be possible. The study was done in male school going children only as the investigators (male) were not allowed in to girl schools.

\section{CONCLUSION}

Average BMI for the school students is in the category of pre-obese and fast food consumption also was found to be high in the adolescents. The most successful schoolchildren were those who consumed more fruits and vegetables and more milk and dairy products. Parent's education seems to be influencing education. Quality food is lacking in the diet of children affecting the academic performance. So proper awareness is required for the guardians regarding the diet of the children.

\section{Recommendations}

Baseline assessment of nutrition in the schools should be made mandatory. Every school have to be informed to develop a food and nutrition policy. Awareness of good and bad nutrition need to be given to the students.

\section{ACKNOWLEDGEMENTS}

The research team would like to thank the Deanship of Scientific Research for giving this opportunity and funding to do this research. The team expresses sincere gratitude to the school authority for giving the permission.

Funding: Deanship of Scientific Research, Jazan University, Jazan, KSA

Conflict of interest: None declared

Ethical approval: All ethical approvals taken from the Jazan University

\section{REFERENCES}

1. Ogunsile SE. The Effect of Dietary Pattern and Body Mass Index on the Academic Performance of In-School Adolescents. International Education Studies. 2012;5(6):65-72.

2. Taghizadeh Moghaddam H, Bahreini A, Ajilian Abbasi M, Fazli F, Saeidi M. Adolescence Health: the needs, problems and attention. International $\mathrm{J}$ Pediatrics. 2016;4(2):1423-38.

3. Handa R, Ahamad F, Kesari KK, Prasad R. Assessment of nutritional status of 7-10 years school going children of Allahabad district: A review. Middle-East J Scien Res. 2008;3(3):109-15.

4. Taras H. Nutrition and student performance at school. J School Health. 2005;75(6):199-213.

5. Galal O, Hulett J. The relationship between nutrition and children's educational performance: a focus on the United Arab Emirates. Nutrition Bulletin. 2003;28(1):11-20. 
6. Kretchmer N, Beard JL, Carlson S. The role of nutrition in the development of normal cognition. American J Clin Nutr. 1996;63(6):997-1001.

7. Meyers A, Sampson A, Weitzman M. Nutrition and academic performance in school children. Clin Appl Nutr. 1991;1:13-25.

8. Pollitt E, Mathews R. Breakfast and cognition: an integrative summary. American J Clin Nutr. 1998;67(4):804-13.

9. Morley CE. Neurotransmitters and nutrition. Orthomolecular Psychiatry. New York: McGraw Hill Book. Company; 1981;12:38-43.

10. Toga AW, Thompson PM, Sowell ER. Mapping brain maturation. Focus. 2006;29(3):148-390.

11. Boateng AC. Prevalence of Malnutrition among Children 1-8 Years in Ghana: Amansie West District of Ghana.

12. Glewwe P, Jacoby HG, King EM. Early childhood nutrition and academic achievement: a longitudinal analysis. J Public Economics. 2001;81(3):345-368.

13. Onis DM, Habicht JP. Anthropometric reference data for international use: recommendations from a World Health Organization Expert Committee. American J Clinical Nutr. 1996;64(4):650-8.

14. Alswat KA, Al-shehri AD, Aljuaid TA, Alzaidi BA, Alasmari HD. The association between body mass index and academic performance. Saudi Medical J. 2017;38(2):186.

15. Li Y, Dai Q, Jackson JC, Zhang J. Overweight is associated with decreased cognitive functioning among school-age children and adolescents. Obesity. 2008;16(8):1809-15.

16. Lee Y, Manan WA. Mutritional status, academic performance and parental feeding practices of primary school children in a rural district in Kelantan, Malaysia. Progress Health Sci. 2014;4(1):144-52.

17. Zhang J, Hebert JR, Muldoon MF. Dietary fat intake is associated with psychosocial and cognitive functioning of school-aged children in the United States. J Nutrition. 2005;135(8):1967-73.

18. Abudayya A, Shi Z, Abed Y, Holmboe Ottesen G. Diet, nutritional status and school performance $t$ among adolescents in Gaza Strip. 2011.

19. El-Hazmi MA, Warsy AS. A comparative study of prevalence of overweight and obesity in children in different provinces of Saudi Arabia. J Tropical Pediatrics. 2002;48(3):172-7.

20. Khan SQ, Khan NB, Rejaie AS. Dental caries. Saudi Med J. 2013;34(7):744-9.

Cite this article as: Khan M, Shanawaz M, Altoaibi AA, Gaba AAB, Saqeeh OI, Mashali ARA. Assessment of nutritional status and its effect on academic performance in school children of Jazan, Kingdom of Saudi Arabia. Int J Community Med Public Health 2020;7:1234-9. 